\title{
'A teacher is no politician': Stereotypic attitudes of secondary school teachers in Kenya
}

\author{
Line Kuppens $^{\mathrm{a}, \mathrm{b}, *}$, Arnim Langer ${ }^{\mathrm{a}, \mathrm{c}}$, Sulley Ibrahim ${ }^{\mathrm{a}}$ \\ ${ }^{\text {a }}$ Centre for Research on Peace and Development (CRPD), KU, Leuven, Belgium \\ ${ }^{\mathrm{b}}$ Institute of Development Policy (IOB), University of Antwerp, Belgium \\ ${ }^{\mathrm{c}}$ Alexander von Humboldt Fellow, University of Heidelberg, Belgium
}

\section{A R T I C L E I N F O}

\section{Keywords:}

Stereotyping

Teachers

Inter-group attitudes

Kenya

Peace education

\begin{abstract}
A B S T R A C T
More than affecting their academic performance, teachers' stereotypic attitudes may impact society at large by shaping pupils' inter-group attitudes. Whereas particularly teachers in post-conflict and divided societies may have negative inter-group attitudes, extremely little research has been conducted in these contexts. Based on a large-scale survey of secondary school teachers $(\mathrm{N}=925)$ and 68 in-depth follow-up interviews in Nairobi, this paper aims to address this void by examining teachers' inter-group attitudes in Kenya, an ethnically divided society. While their attitudes appear to be stereotype-congruent, we find that Kenyan teachers seem careful of not letting their own stereotypes influence their teaching practices.
\end{abstract}

\section{Introduction}

Stereotypes about ethnic groups are very prominent in the diverse society of Kenya, which is home to more than 40 ethnic groups among which the Kikuyu, Luhya, Luo, Kalenjin, and Kamba are predominant (e.g. Branch, 2011; Ishiyama et al., 2016). Stereotypes are overgeneralizations of character traits to group members (Allport, 1958; Hamilton et al., 2009, p. 179). Often heard stereotypes in Kenya include the exploitative money-loving Kikuyu; the intelligence, as well as the aggressiveness of the Luo; and the stereotype that Maasai value nothing more than they value cattle and grass (Hornsby, 2013, p. 788; Ndonye et al., 2015, p. 47-48). Whereas stereotypes are commonly used to make jokes, they have become entrenched within Kenyan politics and have been used as a tool to fuel ethnic hatred, as was the case during the 2007-2008 post-electoral violence. Violence erupted after opposition leader Raila Odinga, a Luo, contested the electoral victory of incumbent president Mwai Kibaki, a Kikuyu, and largely opposed the ethnic following of the two leaders (HRW, 2008; Ndonye et al., 2015, p. 48; Yieke, 2008).

Stereotypes can be random and meaningless, but they may also foster prejudice, a generally negative evaluation of, and/or attitude towards members of a group (e.g. Albarracin et al., 2008, p. 19; Allport, 1958, p. 8; Beelmann and Heinemann, 2014; Stangor, 2009, p. 2). Such negative inter-group attitudes are associated with diverse social problems, such as social exclusion and discrimination, and can even contribute to inter-group conflict, of which the Kenyan post-election violence is an example (e.g. Beelmann and Heinemann, 2014, p. 10; Brown and Bigler, 2002, p. 79; Reyna, 2000, p. 86). To avoid these vices, researchers have studied ways to improve inter-group attitudes, including inter-group contact (e.g. Allport, 1958; Pettigrew and Tropp, 2011).

Many prejudice-reducing interventions are set in a school context given that schools play an important role in shaping the political and social attitudes of young people (e.g. Jennings and Niemings, 1974; Torney-Purta, 2002). Examples range from integrated schooling, bilingual education, multicultural education, and training on social-cognitive skills and role-playing (Aboud and Levy, 2000; Beelmann and Heinemann, 2014). Peace education, likewise, seeks to improve intergroup attitudes and perceptions, and to foster greater tolerance between (formerly) opposing groups in divided and post-conflict societies through school (e.g. Salomon and Nevo, 2002). In Kenya, a Peace Education course was introduced at the primary and secondary level in the aftermath of the post-electoral violence to 'equip young people with requisite knowledge, skills and attitudes for building peace as well as values for constructive intrapersonal, interpersonal and intergroup relations at the national and international levels' (Ministry of Education, Science and Technology, 2014, p. 2). ${ }^{1}$

These interventions commonly target pupils. Teachers may have negative inter-group attitudes too, however. Like their pupils, teachers

\footnotetext{
* Corresponding author at: Institute of Development Policy, University of Antwerp, Prinsstraat 13, 2000, Antwerpen, Belgium.

E-mail addresses: line.kuppens@uantwerpen.be (L. Kuppens), arnim.langer@soc.kuleuven.be (A. Langer), sulley.ibrahim@kuleuven.be (S. Ibrahim).

${ }^{1}$ While a separate course was introduced at the primary level, content on Peace Education was integrated in other courses, such as life skills, religion, social studies, and history and government at the secondary level (Smith et al., 2016, 71).
} 
belong to cultural communities that define their identity, views, and attitudes, which in turn influence their behaviour (see Horner et al., 2015; Kumar et al., 2015; Kuppens and Langer, 2016). Large-scale research on teachers' stereotypes in Western settings has shown, for example, that teachers' inter-group attitudes inform their behaviour and, by consequence, impact pupils' academic achievement and wellbeing in the classroom (see e.g. Chang and Demyan, 2007; Tenenbaum and Ruck, 2007). Yet, to our knowledge, there are no large-scale studies that have analysed teachers' inter-group attitudes in post-conflict and divided societies. Teachers in these contexts would, nevertheless, be much more likely to harbour negative inter-group attitudes as they have experienced inter-group tensions, and, possibly, violence (e.g. Bentrovato et al., 2016; Zembylas et al., 2016). Likewise, their negative inter-group attitudes may be considerably stronger than those of teachers living in relatively peaceful societies. On top of affecting the wellbeing and achievement of pupils, such negative inter-group attitudes could, if left unaddressed, compromise the peace education and prejudice-reducing programs in these countries: Instead of acting like role models who exemplify positive inter-group attitudes (Bar-Tal, 2002), teachers portraying negative inter-group attitudes could stimulate rather than dissuade prejudices and stereotypes among their pupils (Bekerman \& McGlynn, 2007, in Zembylas et al., 2012, p. 1073; Bush and Saltarelli, 2000; Zembylas et al., 2016).

The current article examines to what extent these concerns are empirically supported by analysing the inter-group attitudes of secondary school teachers in the divided society of Kenya. The analyses are based on a sample of 925 secondary school teachers collected by the authors between April and June 2016 in 64 secondary schools in Nairobi, as well as in-depth follow-up interviews with a subsample of 68 teachers. While the survey shows that they do have stereotypic attitudes, teachers attest in the in-depth interviews that they are careful not to let such attitudes inform their behaviour.

The article will proceed as follows. First, we briefly review the theory on stereotypes (Section 2), and discuss why teachers and their inter-group attitudes matter to the success of peace education and prejudice-reducing programs (Section 3). Section four, next, introduces the case study of Kenya, while Section 5 presents the data and methodology. Afterwards, we analyse and discuss the results of the survey. Section six concludes.

\section{Stereotypes}

People inevitably think in groups or categories in order to simplify and anticipate an otherwise overwhelmingly complex social environment (e.g. Allport, 1958, p.19; Devine and Sharp, 2009, p.61; Reyna, 2000, p.92). Once these groups are formed, they tend to be very stable given that people are attentive to differences between groups, while minimizing within-group differences (Brewer and Miller, 1996). Stereotypes, then, are the sets of knowledge, beliefs and expectancies that we attribute to social groups, and that we apply to all group-members irrespective of their individual differences (Hamilton et al., 2009, p. 179; Reyna, 2000, p. 92). They are overgeneralizations of character traits to group members (Hamilton et al., 2009, p. 179) or 'exaggerated beliefs' about those group members (Allport, 1958, p. 187). Stereotypes are closely interrelated with prejudice and discrimination - the three components of inter-group attitudes. Whereas stereotypes represent the cognitive component of intergroup attitudes (attributing a characteristic), prejudice and discrimination respectively represent the emotional (e.g. antipathy or dislike) and behavioural component (e.g. excluding, insulting) (e.g. Beelmann and Heinemann, 2014; Devine, 1989).

People rely on stereotypes to judge members from other groups and to anticipate their behaviour. They do so particularly when group membership - often ethnic or religious group membership (see McKown and Weinstein, 2008, p. 238), is the only information they have about a person or whenever they are not interested in getting to know the person better (Glock and Krolak-Schwerdt, 2014, p. 590; Stangor, 2009, p. 10). Stereotypes thus raise expectations that, in turn, inform our behaviour. As such, stereotyping has consistently been found to lead to out-group discrimination (Brown and Bigler, 2002, p. 79; Reyna, 2000, p. 86; Stangor, 2009, p. 5). ${ }^{2}$ Discrimination can take many forms, ranging from exclusion of out-group members, to the absence of showing positive affect towards the out-group, such as sympathy and trust (Brewer and Miller, 1996, p. 75), or the withholding of prosocial behaviour, such as helping and cooperation (Brewer and Miller, 1996, p. 5).

While group-membership automatically activates stereotypes, people can 'correct' for their bias towards other groups if they are aware of its existence. Indeed, while attitudes usually spontaneously guide behaviour, people can deliberately take into consideration their attitudes and their behavioural consequences and decide not to act in conformity (e.g. Devine, 1989; Fazio, 1990; Wegener \& Petty, 1995 in Olson and Kendrick, 2008, p. 120). Merely holding stereotypes, hence, is not necessarily problematic, yet applying them is (Stangor, 2009, p. 5).

\section{Why teachers matter}

Like anybody else, teachers rely on stereotypes. This can be problematic in a classroom setting. Pupils' group characteristics may activate stereotypical information that, if not corrected for, will trigger stereotype-congruent expectations and behaviour on behalf of the teacher (Reyna, 2000, p. 87). This phenomenon is commonly known as the 'Pygmalion effect', named after the seminal study on the effects of interpersonal expectations in the classroom by Rosenthal and Jacobsen (1968). The effects of interpersonal expectations have been studied widely ever since. Teachers were found, for example, to expect less from students belonging to stereotyped groups than from pupils from non-stereotyped groups with a similar performance record (McKown and Weinstein, 2008; Glock and Krolak-Schwerdt, 2014; van den Berg et al., 2010; van Ewijk, 2011); to evaluate their performances poorer (e.g. Guttmann and Bar-Tal, 1982; Jussim and Harber, 2005; Riley and Ungerleider, 2012); to punish them more severely (Dunkake and Schuchart, 2015); and to have less supportive relations with pupils from stereotyped groups (Thijs and Fleischmann, 2015). Even small cues, such as students' names, were found to cause such effects (Figlio, 2005; Riley and Ungerleider, 2012). Often presented as dramatic and ubiquitous, it is important to note that these effects are generally small, though significant, and vary depending on the context (i.e. location), the information teachers have acquired about their learners (increasing as teachers get to know their pupils), as well as by pupils' and teachers' group membership (e.g. Jussim and Harber, 2005; Tenenbaum and Ruck, 2007; Dunkake and Schuchart, 2015). Nor do all teachers hold differential expectations and act accordingly, but mainly those with negative prejudiced attitudes (van den Bergh et al., 2010).

Pupils, in turn, are likely to sense teachers' expectations and internalize them, which may decrease their self-esteem and affect their performances (e.g. Agirdag et al., 2012; McKown and Weinstein, 2008). More generally, when pupils are confronted with a situation to which a stereotype applies, they fear to conform to the existing stereotype or to be judged accordingly. Steele (1997) accurately defined this phenomenon as the 'stereotype threat', or 'the threat that others' judgments or their own actions will negatively stereotype them in the domain' (Steele, 1997, p. 613).

In this way, teachers' expectations, notwithstanding their accuracy, are likely to trigger the behaviour they anticipate, thereby perpetuating and cementing existing stereotypes (Gershenson et al., 2016; van den Bergh et al., 2010): When teachers' stereotype-congruent expectations are based on false conceptions and cause a new behaviour, expectancy effects act as self-fulfilling prophecies. Whenever stereotype-congruent expectations are based on 'real' differences, on the other hand, they perpetuate low

\footnotetext{
${ }^{2}$ Out-groups comprise all categories different from the categories the perceiver belongs to, which are called, by contrast, the in-group(s) (Brewer and Miller, 1996, p.6).
} 
expectations and are referred to as self-maintaining expectations (van den Bergh et al., 2010, p. 500). Furthermore, teachers influence pupils' intergroup attitudes merely by reason of their authority and their role as 'secondary attachment' figures, providing pupils with support and emotional security (Thijs and Verkuyten, 2012, p. 261).

Teachers can also suppress their stereotypical expectations (Glock and Krolak-Schwerdt, 2014; van Ewijk, 2011, p. 1046), or even discourage stereotypes, both actively as well as passively. Mere contact of in-group pupils with an out-group teacher, for example, can facilitate out-group learning and reduce inter-group anxiety, at least if the relationship is characterized by mutual trust and positive affect (Allport, 1958; Pettigrew and Tropp, 2011). ${ }^{3}$ Such inter-group contact would have a greater impact on inter-group attitudes than teaching pupils about ethnic diversity (Thijs and Verkuyten, 2012, p. 266). Inter-group contact does not, however, diminish children's in-group bias (Brown and Bigler, 2002, p. 91), ${ }^{4}$ and risks to strengthen group boundaries and confirm stereotypes in the rare case that the contact experience is negative (see Albarracin et al., 2008, p. 21; Thijs and Verkuyten, 2012, p. 261). Teachers can also actively discourage stereotyping by 'correcting' for their stereotypes, or by introducing prejudice-reducing topics in the classroom.

If teachers' stereotypes are not 'corrected' for, however, peace education and prejudice-reducing programs may be introduced in vain. It is commonly argued in the literature that for peace education programs to be effective, teachers have to practice what they preach (BarTal, 2002; Brewer and Miller, 1996). Particularly teachers in divided and post-conflict societies may have very biased views of 'the other', nevertheless, as they have experienced, or continue to experience, intergroup tensions and conflict themselves (Bar-Tal, 2004, in Zembylas et al., 2012, p. 1073; Kuppens and Langer, 2016). Some of them may even have actively instigated inter-group divisions. Rather than dissuading, teachers in these contexts may stimulate prejudices and stereotypes among their pupils, whether consciously or not. Qualitative studies in the field of peace education have already reported instances of stereotyping and discriminatory behaviour by teachers in post-conflict and divided societies (see e.g. Bekerman \& McGlynn, 2007, in Zembylas et al., 2012, p. 1073; Bush and Saltarelli, 2000; Zembylas et al., 2016). So far, there are no studies, however, that have studied teachers' stereotypic attitudes in divided or post-conflict societies on a large scale. Quantitative research could, nevertheless, give insight into the extent and deep-rootedness of the phenomenon.

\section{The case study of Kenya}

\subsection{Ethnicity and ethnic stereotyping in Kenya}

More than 40 ethnic communities are living together in Kenya, among which the Kikuyu, Luhya, Luo, Kalenjin, and Kamba are predominant. Whereas the Kikuyu account for about $20 \%$ of the population, the four other groups each represent roughly $10 \%-15 \%$ of the Kenyan population (Branch, 2011, p. 4; Ishiyama et al., 2016, p. 307). In general, ethnic differences in Kenya are apparent in names, appearance, skin colour, and accents (Hornsby, 2013, p. 312). Stereotypes about ethnic groups are very prominent in Kenyan society, and include the untrustworthy money-loving Kikuyu; the intelligence, as well as the aggressiveness of the Luo; the cooking skills of the Luhya; the talent for athletics of the Kalenjin; and the stereotype that Maasai value nothing more than they value cattle and grass, whence the perception that Maasai are primitive (Ndonye et al., 2015, p. 47-48; Hornsby, 2013, p. 788).

\footnotetext{
${ }^{3}$ The positive effects of inter-group contact in a school setting can also emanate from positive contact between pupils from diverse groups, or from relations between pupils and the school administration at large (Agirdag et al., 2014; Thijs and Verkuyten, 2012).

${ }^{4}$ In-group bias is the tendency to evaluate one's in-group better than the outgroup
}

Whereas these stereotypes are commonly used to make jokes, they have become entrenched within Kenyan politics and have even been used to instigate ethnic hatred, particularly around election times (Ndonye et al., 2015, p. 48). The 2007-2008 post-election violence is the most notorious example hereof. In the aftermath of the presidential elections of December 2007, ethnic Kikuyu clashed with Kalenjin warriors and ethnic Luo after then incumbent President Mwai Kibaki, a Kikuyu, won a contested electoral bid by a small margin of 232000 votes from Luo opposition leader Raila Odinga, who until shortly had led the tallies by more than one million votes. The violence caused the death of an estimated 1113 people and wounded another 3561 (Dercon and Guitérrez-Romero, 2012, p. 735; Harneit-Sievers and Peters, 2008, p. 137; HRW, 2008, p. 22). Ethnic hate messages were spread most vehemently via local radio stations and text messaging (Abdi Ismael and Deane, 2008; Makinen and Kuira, 2008, p. 331), and echoed common ethnic stereotypes: Kibaki was referred to as 'a snake we have to get rid of' (HRW, 2008, p. 36) - symbolizing mistrust towards the cunning, money loving Kikuyu (Hornsby, 2013, p. 748), while Odinga was described as 'the beast from the West' (Yieke, 2008, p. 16) - hinting to the idea that the Luo, who are originally from Western Kenya, are violent. It was also said that Odinga was unable to lead given that he is a 'child' (HRW, 2008, p. 4) - contrary to most other ethnic groups in Kenya, the Luo do not practice circumcision to symbolize the transition from child- to manhood.

\subsection{Ethnicity at school}

Policies in Kenya aim to fend schools off from ethnic tensions. Ethnic differences are minimized within the school compound through, among others, the mandatory wearing of a school uniform and the prohibition to speak local languages. ${ }^{5}$ The more, the national goals of education aim to promote national unity (Mwaka et al., 2013). Intergroup contact is promoted through the application of regional quota, at least in public secondary schools. Kenyan public schools are divided into a four-tier hierarchy, ranging from least to most prestigious in terms of access - admission to secondary schooling is based upon pupils' performance on the national exams at the end of primary school (cf. Kenyan Certificate for Primary Education or KCPE). The more prestigious the school, the more diverse is the pupil population: district schools admit principally low-range performing pupils (or, importantly, pupils who cannot financially afford better schools) from within the district; county schools recruit middle-range performing pupils among whom $60 \%$ are from the district the school is located in, $35 \%$ is from other districts within the former province, and 5\% from other former provinces; extra-county schools recruit $40 \%$ of students nationally, $40 \%$ at county level, and $20 \%$ from within the district; national schools, lastly, select the best performing pupils from all over the country (Nyatuka and Bota, 2014). Inter-group contact is also promoted by the national policy on teacher deployment, which encourages teachers to seek deployment outside of their region of origin. Teachers appear reluctant, however, to be posted elsewhere (Smith et al., 2016).

At times ethnic discrimination has nevertheless penetrated the Kenyan school walls. During the post-election violence, in particular, children were asked sensitive ethnic-related questions at school, such as why their community is so rebellious (cf. Luo) or why they are not going to school in Kisumu (the region of origin of the Luo community) (Yieke, 2008, p. 24). Moreover, in areas affected by the violence, students as well as teachers were forced to leave school for safety reasons (Smith et al., 2016, p. 68). This suggests that the current educational policies and practices do not suffice to keep the country's divisive ethnic politics out of the school compound in times of increased tensions.

\footnotetext{
${ }^{5}$ Pupils can, however, attend the first three years of primary school in their mother tongue.
} 


\section{Stereotyping among secondary school teachers in Kenya}

\subsection{Data}

The current study is part of a larger study on the role of education in building sustainable peace in Kenya, which focuses on the role of teachers in enhancing peaceful relations among formerly opposing groups through a mixed-method approach. A large-scale survey was conducted between April and June 2016 among 925 secondary school teachers in Nairobi. ${ }^{6}$ During the post-electoral violence of $2007-2008$, the capital city was one of the pockets where ethnic violence took place, next to areas in former Western province, Nyanza and the Rift Valley (HarneitSievers and Peters, 2008, p. 133). In addition to its history of ethnic tensions, it is an interesting case study given that all types of schools can be found there in proximity. The survey was self-administered on a tablet, using the software package 'Qualtrics' (Qualtrics LLC, Provo, Utah). Additionally, in-depth follow-up interviews were conducted with 68 teachers to gain deeper insights into the data collected.

Schools were selected systematically by number of pupils after stratification by district and type of school. ${ }^{7}$ In total, 64 secondary schools were selected among the 258 recognized schools (176 private and 82 public schools). ${ }^{8}$ Upon an introductory visit to the school, all school heads agreed to participate and their schools effectively took part in the study. Schools varied largely in size: the smallest school in the sample taught only 21 pupils, while 1500 students attended the largest school $(\mathrm{M}=384.86, \mathrm{SD}=390.229)$. In terms of teacher deployment, schools deployed 21 teachers on average $(\mathrm{Min}=5$, $\operatorname{Max}=80, \mathrm{SD}=18.443$ ). Table 1 summarizes school characteristics.

Within every school, all teachers were invited to participate. However, only those teachers participated who were present at the time of the survey. Schools, in which less than half of all teachers participated, were visited multiple times. Sporadically, teachers refused participation because of their workload (cooperation rate of nearly $100 \%$ and response rate of 69\%). Item non-response, on the other hand, was avoided by the use of tablets. ${ }^{9}$ In total, 925 teachers participated. Table 2 summarizes the ethnic background of the teachers.

\subsection{Methodology}

To measure teachers' inter-group attitudes, we make use of three semantic-differential scales on an 11-point scale ranging from -5 to 5 with 0 indicating a neutral position: e.g. untrustworthy-trustworthy, unintelligent-intelligent, violent-gentle. For the purpose of subsequent analyses, ratings were recoded from a scale of -5 to 5 , to a scale of 0 to 10 . Although a relatively 'old-fashioned' measure, the use of this scale remains predominant in inter-group research in Africa (see e.g.Tropp et al., 2017; Rimé et al., 2011) - to large degree because ethnic groups are many and inter-group differences are not necessarily visible. Moreover, the realities of the terrain, such as logistical constraints and respondents' computerliteracy, make the use of more advanced methods (e.g. Implicit Association Test, affective priming) more complicated.

Teachers rated the following ethnic groups: Kikuyu, Luo, Kalenjin, and Maasai. The first three groups were chosen because of their share in the population, as well as their prominence in the political history of and public debate in Kenya. Whereas the Luhya and Kamba also represent important shares of the population, these groups were not included in the survey since, unlike the previous three, they have not been mobilized

\footnotetext{
${ }^{6}$ The research was approved by the National Commission for Science, Technology and Innovation, and by all the District Education Offices involved.

${ }^{7}$ A list of schools was obtained from the Ministry of Education in March 2016.

8 Two selected schools did not appear to exist any longer and were replaced.

${ }^{9}$ To proceed, teachers had to respond to each question. Neutral response categories were provided.
}

Table 1

Descriptive Statistics of school characteristics $(\mathrm{N}=64)$.

\begin{tabular}{|c|c|c|c|}
\hline Variables & $\%$ & & $\%$ \\
\hline \multicolumn{4}{|c|}{ Location of school: } \\
\hline Dagoretti & 20.3 & Kasarani & 12.5 \\
\hline Embakasi & 17.2 & Njiru & 6.3 \\
\hline Lang'ata & 12.5 & Starehe & 12.5 \\
\hline Makadara & 4.7 & Westlands & 9.4 \\
\hline Kamukunji & 4.7 & & \\
\hline \multicolumn{4}{|l|}{ Statute of school: } \\
\hline Public & 39.1 & Private & 60.9 \\
\hline \multicolumn{4}{|l|}{ Type of school: } \\
\hline National & 9.4 & District & 20.3 \\
\hline Extra-county & 1.6 & Private school & 40.6 \\
\hline County & 28.1 & & \\
\hline \multicolumn{4}{|c|}{ Day or boarding school: } \\
\hline Day & 59.4 & Mixed & 23.4 \\
\hline Boarding & 17.2 & & \\
\hline \multicolumn{4}{|c|}{ Girls/boys school: } \\
\hline Girls & 12.5 & Mixed & 70.3 \\
\hline Boys & 17.2 & & \\
\hline \multicolumn{4}{|l|}{ State of school ${ }^{\text {a }}$} \\
\hline Poor & 20.3 & Good & 23.4 \\
\hline Decent & 45.3 & Excellent & 10.9 \\
\hline \multicolumn{4}{|c|}{ Average score of school in national exams: ${ }^{b}$} \\
\hline B & 16.7 & $\mathrm{D}$ & 48.3 \\
\hline $\mathrm{C}$ & 35 & & \\
\hline
\end{tabular}

a Defined by interviewer based on the following indicators: computer availability, TV availability, library in school, Internet connection, sports facilities, socio-economic status of the direct neighbourhood, and affluence of the school.

b None of the participating schools attained an average score 'A'.

Table 2

Descriptive Statistics of teacher characteristics $(\mathrm{N}=925)$.

\begin{tabular}{|c|c|c|c|c|}
\hline Variables & $\%$ & Min. & Max. & M (SD) \\
\hline \multicolumn{5}{|l|}{ Sex: } \\
\hline Male & 52.2 & & & \\
\hline Female & 47.8 & & & \\
\hline \multicolumn{5}{|l|}{ Religion: } \\
\hline Christian & 95.5 & & & \\
\hline Muslim & 0.8 & & & \\
\hline Other & 3.8 & & & \\
\hline \multicolumn{5}{|l|}{ Ethnic group: } \\
\hline Kikuyu & 21.1 & & & \\
\hline Luo & 18.5 & & & \\
\hline Luhya & 19.1 & & & \\
\hline Kalenjin & 4.4 & & & \\
\hline Kamba & 10.4 & & & \\
\hline Kisii & 11.4 & & & \\
\hline Meru & 4.2 & & & \\
\hline Other & 10.9 & & & \\
\hline \multicolumn{5}{|c|}{ Subjects taught (combinations possible): } \\
\hline Language courses & 35.1 & & & \\
\hline Exact sciences & 43.9 & & & \\
\hline Social sciences & 42.5 & & & \\
\hline Other courses & 37 & & & \\
\hline Age & & 19 & 83 & 33.04 (9.97) \\
\hline Years of teaching & & 0 & 63 & $9.39(9.21)$ \\
\hline
\end{tabular}

ethnically due to the absence of a strong ethnic leadership and because of their peripheral position in Kenya's power play (Battera, 2012, p. 123). The Maasai, then, were included in spite of their low population share because of the strong and topical stereotype surrounding the group: being perceived as backward may have a particularly detrimental impact on their experiences at school. We expect teachers' responses on these semantic-differential scales to reflect common stereotypes. As such, we hypothesize that teachers rate Kikuyu as untrustworthy; Luo as intelligent, and violent; and Maasai as unintelligent. Moreover, in line with Western research findings, we hypothesize that teachers are prone to an in-group bias. Given that semantic-differential scales measure explicit attitudes, it is 
important to keep in mind that teachers' responses may be affected by a social desirability and self-presentation bias (e.g. van den Bergh et al., 2010): informed by societal norms and expectations regarding the research, teachers may have provided those responses that they believe are socially acceptable and that present themselves in a good light, instead of their true attitudes. Surprisingly, in-group bias in DR Congo was, however, found to be more outspoken when using explicit rather than implicit measures (Lowes et al., 2017).

We are also interested in the strength of teachers' stereotypes and how it varies between teachers and schools. At the level of the teacher, we estimate the impact of ethnicity and control for effects of age, gender, and level of education. In line with previous research, we expect that older, male, and less educated teachers are more prejudiced than younger, female, and higher educated teachers (see Meeusen and Kern, 2016, p. 6). We also control for teachers' teaching experience. At the level of the school, next, we are interested in examining whether the strength of stereotypic attitudes depends on the level of school diversity. In line with previous research, we hypothesize that stereotypic attitudes weaken as schools become more diverse. In the absence of any data on pupils' ethnic background, we use type of school as a proxy for ethnic diversity because of the use of regional entry quota. The quotas only apply to public schools, nevertheless.

Since the data is nested, we make use of multilevel modelling (multilevel package in RStudio version 1.0.136). Level 1 represents the within-individual target-specific stereotypic attitude; level 2 denotes the between-teachers component and refers to the differences between teachers in terms of stereotypic attitudes averaged across target ethnic groups; while level 3 is the school-level component, referring to differences between schools with regard to teachers' general stereotypic attitudes (See Fig. 1). Instead of a single dataset, we use a separate dataset for every semantic scale to simplify the analyses (i.e. untrustworthy-trustworthy; unintelligent-intelligent; violent-gentle; $\mathrm{n}=3$ 700 per semantic-differential format: 925 teachers $\times 4$ ethnic groups).

\subsection{Results}

\subsubsection{Stereotypic attitudes}

Graph 1 visualizes the aggregated mean scores of the semantic differential (SD) scale values of each target-specific stereotype, excluding in-group scores. ${ }^{10}$ They illustrate that teachers' inter-group attitudes are conform to stereotypes in Kenyan society. In line with the stereotypes, Kikuyu are perceived to be the least trustworthy; Luo are rated the most intelligent, as well as violent; and Maasai are perceived to be the least intelligent. Teachers' attitudes are not very outspoken, however. Future research is needed to examine whether or not these results are affected by a social desirability or self-presentation bias.

visualize the mean semantic differential (SD) scores of target-specific stereotypic attitudes by teachers' in-group or out-group belonging. Comparing the ratings of in-group and out-group teachers, we notice a clear in-group bias. ${ }^{11}$ It is interesting to note that even the ratings of one's own group are affected by the prevailing stereotypes: whereas the Kikuyu, for example, rate their own group more trustworthy than other groups do, their own score is still lower than the ratings Luo and Kalenjin attribute to their own groups.

To test whether these differences are significant, we fit a three-level model including ethnic group targeted and teachers' in- or out-group belonging as fixed effects. We first fit the unconditional models, which yield estimates of the degree of variance attributable to the different levels per

\footnotetext{
${ }^{10}$ sdRplot by Justine Leon A. Uro is licensed under a Creative Commons Attribution 4.0 International License. Based on a work at https://github.com/ justineuro/sdRplot.

${ }^{11}$ We could not calculate the in-group bias of the Maasai since there were only a few Maasai teachers. These teachers were grouped with teachers from other nomadic communities.
}

Level 3: Differences in teachers' general stereotypic attitudes between $\mathrm{SCHOOLS}$

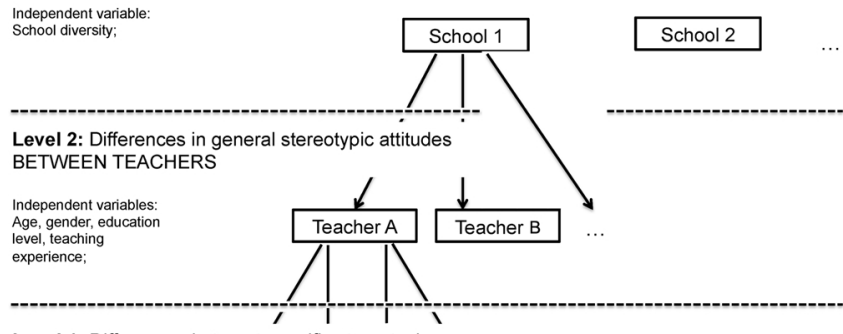

Level 1: Differences in target-specific stereotypic

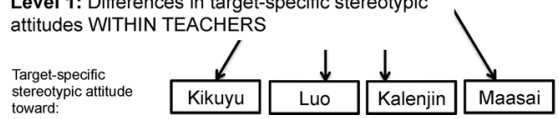

Fig. 1. Design of the multilevel structure.

semantic-differential scale (see Table 3). Schools do not seem to contribute much variance - the Intraclass Correlation Coefficient of schools is at maximum 0.01 (in the case of the violent-gentle scale). ${ }^{12}$ The proportion of variance between teachers, on the contrary, amounts to respectively $28.5 \%, 39.3 \%$ and $40 \%$ for the scales on trustworthiness, intelligence, and violent-gentle behaviour. Next, we add the fixed effects. The results in Table 3 show that teachers effectively rely on stereotypes to judge the different ethnic groups: Kikuyu are perceived to be significantly less trustworthy than other groups; Luo are rated significantly more intelligent, as well as violent; and Maasai are perceived least intelligent. Likewise, the effect of in-group belonging is significant.

Similar stereotypic attitudes were expressed during the follow-up interviews:

The Kikuyu tend to view themselves as the business minded people. Whenever it comes to matters of doing business, they want to make profit. So whenever it comes to that side, they look at them as untrustworthy, not as hardworking. (Male, 25 years old, Embakasi)

In our country, mostly, the ones who will go to the streets are the Luo. They want to fight and they want to throw stones. I think it is their nature. (Female, 33 years old, Langa'ata)

When you are known to be a Maasai, they consider them to be illiterate. So when they come with those attires, they won't [hesitates]. Ok, most people won't look beyond their attires. They just look at what they have in their mind. They just treat them generally as, they consider them as illiterate and more concerned with pastoralism. Learning, there is little learning with them. (Male, 24 years old, Kasarani)

Interestingly, teachers were often quick to try to refute stereotypes after expressing them. After confirming the stereotype of the violent Luo, the above teacher continued, “when we come to school, I don't really have cases of the Luo being more violent. It is probably based on the political view, but in school, they don't fight." Interestingly, a number of teachers also put these stereotypes in historical perspective. For example,

Once the first President of Kenya, Jomo Kenyatta, was a Kikuyu, then the vice-President was a Luo. So they view that since the vice-President who was a Luo was the one who helped Kenyatta to go the presidency, they wanted it back [...] Again, there was that union between the Kikuyu and the Luo in 2002 when we had the Luo and the Kikuyu united for the same post. After going for the same post, then they had an agreement that you go for President, so the Kikuyu go for President and the Luo will go for the Prime Minister. After the Kikuyu went for President, they never gave room for the Prime Minister. [...] So they tend to view a certain group as untrustworthy because they never gave back the work they had agreed. (Male, 25, Embakasi)

\footnotetext{
12 The Intra-Class correlation corresponds to the ratio of the between-cluster variation to the total variance.
} 


\section{Mean Semantic-Differential Scale Values of Target-specific Stereotypic Attitudes}

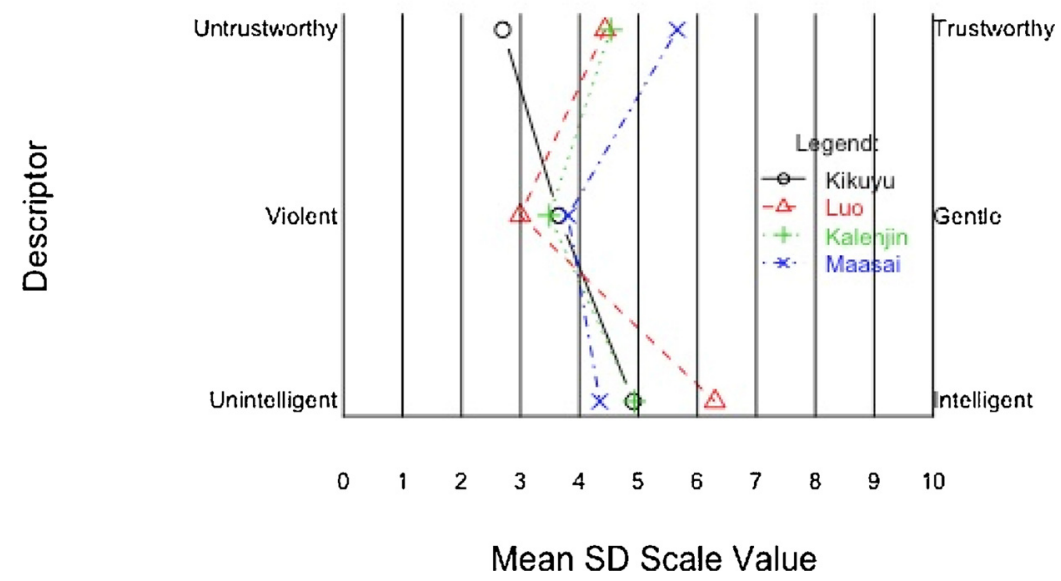

Graph 1. Mean Semantic Differential Scale Values of Target-specific Stereotypic Attitudes - in-group scores excluded (n = 3 273).

\section{Mean SD Scale Values: Kikuyu}

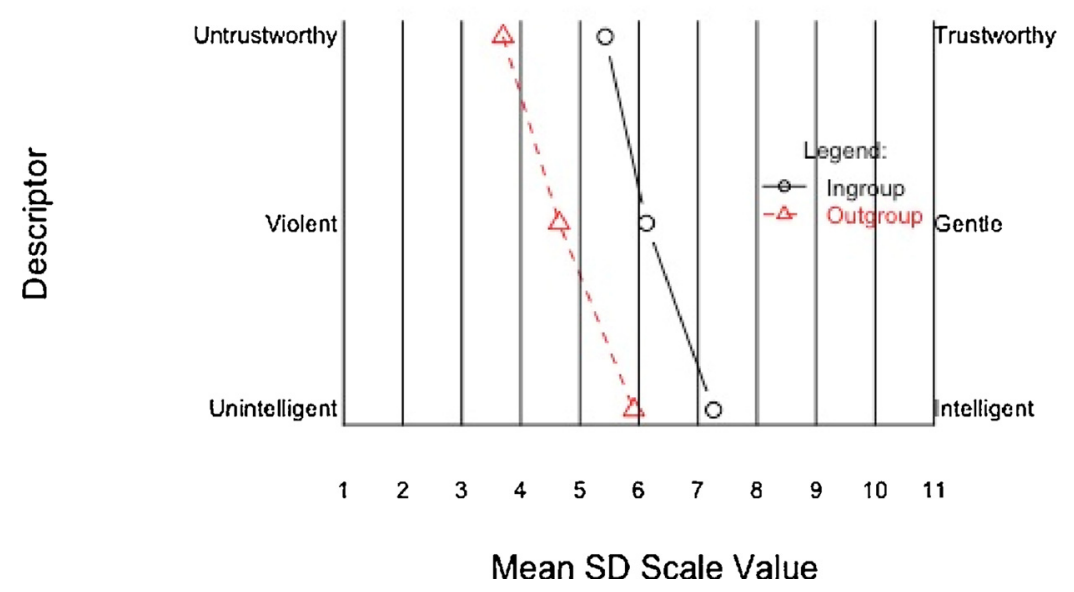

Graph 2. Mean Semantic Differential Scale Values: Kikuyu (n = 3 700).

\section{Mean SD Scale Values: Luo}

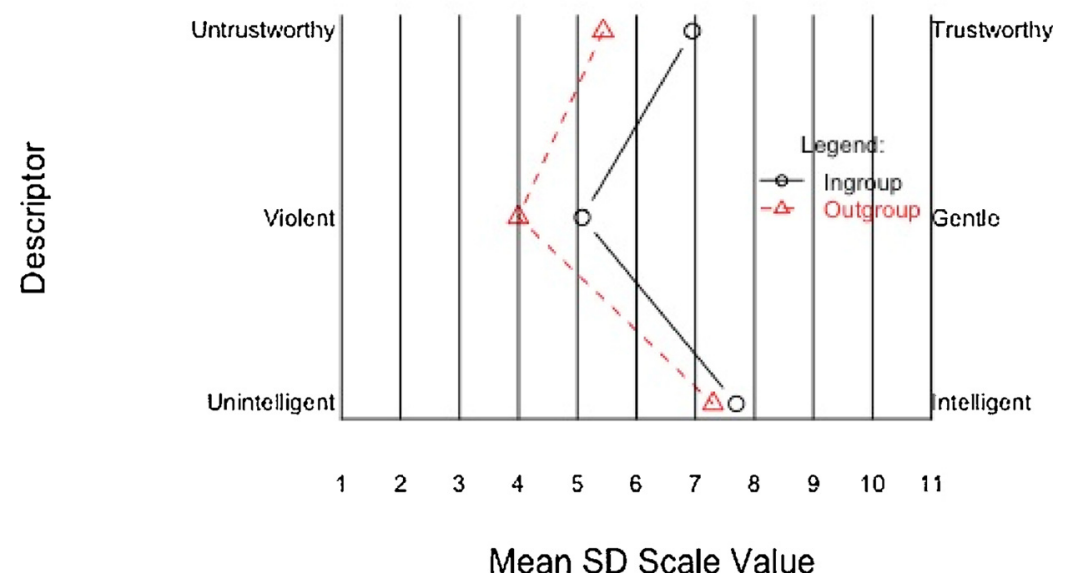

Graph 3. Mean Semantic Differential Scale Values: Luo $(n=3700)$. 


\section{Mean SD Scale Values: Kalenjin}

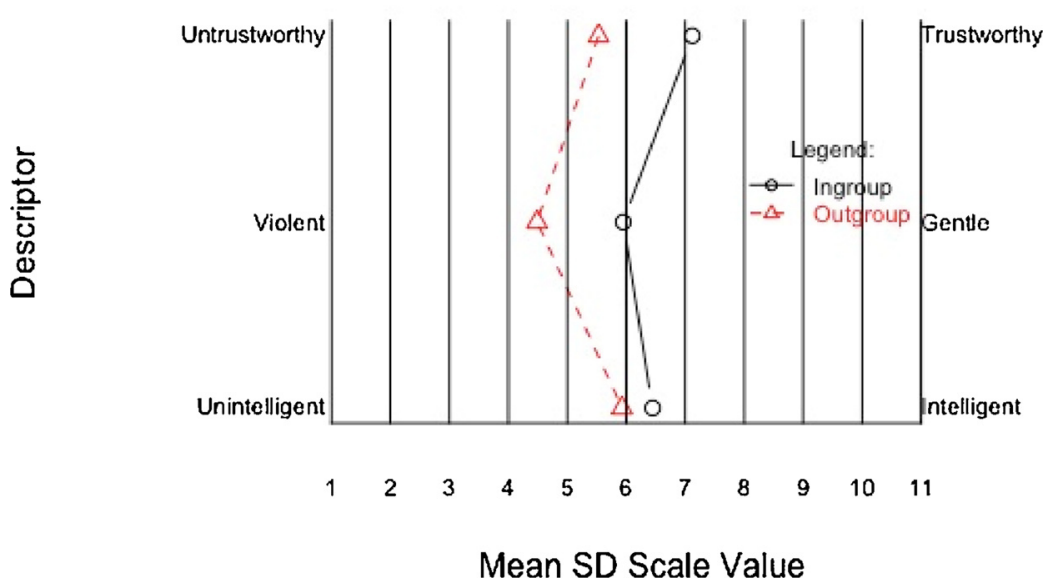

Graph 4. Mean Semantic Differential Scale Values: Kalenjin $(n=3700)$.

Table 3

Multilevel effects of ethnic group stereotyped and teachers' group belonging.

\begin{tabular}{|c|c|c|c|c|c|c|}
\hline & \multicolumn{2}{|l|}{ Trustworthiness } & \multicolumn{2}{|l|}{ Intelligence } & \multicolumn{2}{|l|}{ Violent-Gentle } \\
\hline & Null Model & Model 1 & Null Model & Model 1 & Null Model & Model 1 \\
\hline Intercept & $0.52(0.07)^{* * *}$ & $-1.30(0.10)^{* * *}$ & $1.22(0.07)^{* * *}$ & $1.03(0.09)^{* * *}$ & $-0.36(0.08)^{* * *}$ & $-0.31(0.11)^{* *}$ \\
\hline \multicolumn{7}{|l|}{ Fixed Effects ${ }^{\text {a }}$} \\
\hline Luo & & $1.69(0.10)^{* * *}$ & & $1.19(0.08)^{* * *}$ & & $-0.73(0.10)^{* * *}$ \\
\hline Kalenjin & & $1.82(0.10)^{* * *}$ & & $-0.12(0.08)$ & & $-0.19(0.10)$ \\
\hline Maasai & & $2.96(0.11)^{* * *}$ & & $-0.69(0.08)^{* * *}$ & & $0.12(0.10)$ \\
\hline In-group & & $1.71(0.13)^{* * *}$ & & $0.79(0.10)^{* * *}$ & & $1.31(0.12)^{* * *}$ \\
\hline \multicolumn{7}{|l|}{ Variance } \\
\hline $\mathrm{TSS}^{\mathrm{b}}$ & 6.35 & 4.88 & 3.90 & 3.12 & 5.05 & 4.76 \\
\hline Teacher & 2.53 & 2.89 & 2.56 & 2.73 & 3.43 & 3.46 \\
\hline School & 0.00 & 0.00 & 0.06 & 0.06 & 0.09 & 0.09 \\
\hline Deviance & $735.067^{* * *}$ & & $627.36^{* * *}$ & & $170.02^{* * *}$ & \\
\hline
\end{tabular}

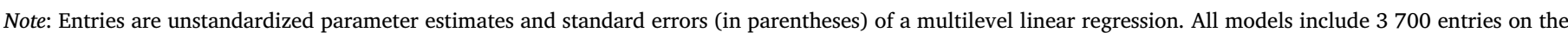
first level, 925 on the teacher level and 64 on the school level; *p $<0.05$, **p $<0.01$, ***p $<0.001$.

${ }^{a}$ Reference categories: Kikuyu (target ethnic group), Out-group belonging (group belonging).

b Target-Specific Stereotypic Attitude (within teacher).

Although interviews are even more susceptible to social desirability and self-presentation biases than semantic-differential scales, it is of significance that teachers describe stereotypes as social constructs that do not necessarily correspond to reality.

\subsubsection{Explaining the strength of stereotypic attitudes}

Since the school-level hardly contributes to the variance in attitudes, it is not surprising that there is no significant effect of school diversity upon addition of the variable 'type of school' (cf. national, extra-county, county, district or private - see Table A1 in Appendix A). While the current data do not support the hypothesis that teachers in more diverse schools have less outspoken stereotypic attitudes, the absence of effect could be due to the characteristics of our sample: all schools are within the highly diverse city of Nairobi and may therefore have a more diverse student population independent of the regional quota. Whereas we have no information on pupils' ethnic background, we can calculate the diversity of the teaching staff as an indicator. Calculation of the Ethnic Fractionalization Index shows that schools' teaching staffs are effectively very diverse (see Fig. 2) ${ }^{13}$ There are three notable exceptions, nevertheless. In three schools, all private, nearly all teachers come from the same ethnic group remarkably, that of their principal.

Interestingly, teachers do identify school diversity as a tool to

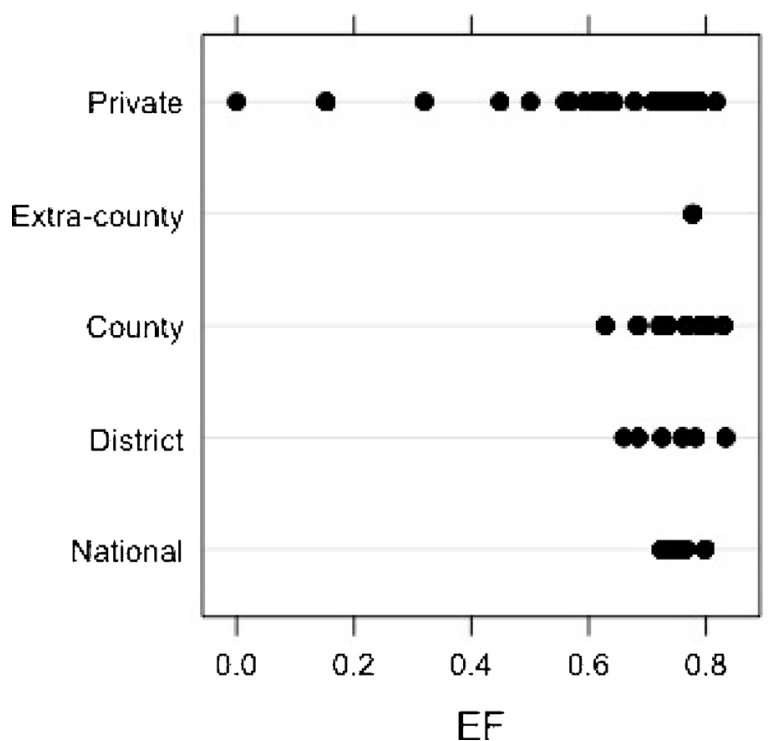

Fig. 2. Diversity of Teaching Staff by School - Ethnic Fractionalization (EF) Index.

\footnotetext{
$\overline{{ }^{13} \text { FRAC }}=1-\sum_{i=1}^{N} \pi_{i}^{2}$
} 
Table 4

Relation between teacher-level variables and semantic-differential scales.

\begin{tabular}{|c|c|c|c|c|c|c|}
\hline & \multicolumn{2}{|l|}{ Trustworthiness } & \multicolumn{2}{|l|}{ Intelligence } & \multicolumn{2}{|l|}{ Violent-Gentle } \\
\hline & I & II & III & IV & $\mathrm{V}$ & VI \\
\hline Intercept & $0.64(0.16)^{* * *}$ & $0.28(0.20)$ & $1.50(0.14)^{* * *}$ & $2.13(0.17)^{* * * *}$ & $0.21(0.17)$ & $1.34(0.21)^{* * *}$ \\
\hline \multicolumn{7}{|c|}{ Level 1: Target-specific stereotypic attitudes (WITHIN teachers) ${ }^{a}$} \\
\hline Luo_1 & & $-0.13(0.20)$ & & $-0.05(0.16)$ & & $-2.23(0.20)^{* * *}$ \\
\hline Kalenjin_1 & & $0.22(0.20)$ & & $-0.91(0.16)^{* * *}$ & & $-1.44(0.20)^{* * *}$ \\
\hline Maasai_1 & & $1.38(0.20)^{* * *}$ & & $-1.53(0.16)^{* * *}$ & & $-0.85(0.20)^{* * *}$ \\
\hline \multicolumn{7}{|c|}{ Level 2: General stereotypic attitudes (BETWEEN teachers) ${ }^{\text {a }}$} \\
\hline Luo_2 & $-0.03(0.21)$ & $-1.76(0.28)^{* * *}$ & $-0.44(0.19)^{*}$ & $-1.66(0.25)^{* * *}$ & $-0.31(0.23)$ & $-1.55(0.29)^{* * *}$ \\
\hline Kalenjin_2 & $-0.02(0.30)$ & $-1.78(0.41)^{* * *}$ & $-0.18(0.28)$ & $-1.16(0.36)^{* *}$ & $-0.32(0.32)$ & $-1.95(0.42)^{* * *}$ \\
\hline Other_2 & $-0.22(0.17)$ & $-1.57(0.23)^{* * *}$ & $-0.44(0.15)^{* * *}$ & $-1.18(0.20)^{* * *}$ & $-0.60(0.18)^{* * *}$ & $-1.55(0.23)^{* * *}$ \\
\hline Age & $-0.01(0.02)$ & $-0.01(0.02)$ & $-0.01(0.02)$ & $-0.01(0.02)$ & $-0.03(0.02)$ & $-0.03(0.02)$ \\
\hline T. Exp. & $0.01(0.02)$ & $-0.01(0.02)$ & $0.01(0.02)$ & $0.01(0.02)$ & $0.02(0.02)$ & $0.02(0.02)$ \\
\hline Gender & $-0.01(0.14)$ & $-0.01(0.14)$ & $0.03(0.13)$ & $0.03(0.13)$ & $-0.39(0.15)^{* *}$ & $-0.39(0.15)^{* *}$ \\
\hline$\geq$ Master & $-0.04(0.19)$ & $-0.04(0.19)$ & $-0.03(0.17)$ & $-0.03(0.17)$ & $-0.10(0.20)$ & $-0.10(0.20)$ \\
\hline Certificate & $-0.08(0.27)$ & $-0.08(0.27)$ & $0.16(0.25)$ & $0.16(0.25)$ & $-0.01(0.29)$ & $0.01(0.29)$ \\
\hline \multicolumn{7}{|l|}{ Cross-level interactions ${ }^{c}$} \\
\hline Luo_1 ${ }^{*}$ Luo_2 & & $3.55(0.31)^{* * *}$ & & $2.28(0.25)^{* * *}$ & & $2.65(0.31)^{* * *}$ \\
\hline Kalenjin_1*Luo_2 & & $1.74(0.31)^{* * *}$ & & $1.23(0.25)^{* * *}$ & & $1.22(0.31)^{* * *}$ \\
\hline Maasai_1*Luo_2 & & $1.62(0.31)^{* * *}$ & & $1.40(0.25)^{* * *}$ & & $1.08(0.31)^{* * *}$ \\
\hline Luo_1 1 Kalenjin_2 & & $1.68(0.46)^{* * *}$ & & $1.44(0.36)^{* * *}$ & & $1.97(0.45)^{* * *}$ \\
\hline Kalenjin_1 *Kalenjin_2 & & $3.38(0.46)^{* * *}$ & & $1.40(0.36)^{* * *}$ & & $3.21(0.45)^{* * *}$ \\
\hline Maasai_1 *Kalenjin_2 & & $2.00(0.46)^{* * *}$ & & $1.07(0.36)^{* * *}$ & & $1.34(0.45)^{* *}$ \\
\hline Luo_1*Other_2 & & $2.11(0.25)^{* * *}$ & & $1.49(0.20)^{* * * *}$ & & $1.73(0.24)^{* * *}$ \\
\hline Kalenjin_1 ${ }^{*}$ Other_2 & & $1.68(0.25)^{* * *}$ & & $0.72(0.20)^{* * *}$ & & $1.23(0.24)^{* * *}$ \\
\hline Maasai_1*Other_2 & & $1.62(0.25)^{* * *}$ & & $0.73(0.20)^{* * *}$ & & $0.81(0.24)^{* * *}$ \\
\hline \multicolumn{7}{|l|}{ Variance } \\
\hline TSSA & 6.34 & 4.86 & 3.90 & 3.07 & 5.01 & 4.70 \\
\hline Teacher & 2.55 & 2.92 & 2.55 & 2.76 & 3.47 & 3.55 \\
\hline AIC & 18081.18 & 17379.58 & 16601.04 & 15977.56 & 17554.17 & 17407.39 \\
\hline BIC & 18149.43 & 17522.19 & 16669.29 & 16120.17 & 17622.41 & 17550 \\
\hline
\end{tabular}

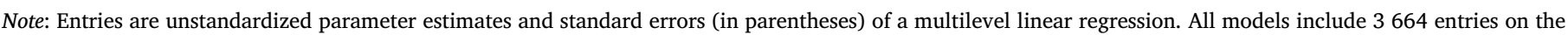
first level and 916 on the teacher. Significance levels: ${ }^{*} \mathrm{p}<0.05,{ }^{* *} \mathrm{p}<0.01,{ }^{* * *} \mathrm{p}<0.001$.

a Reference categories: Kikuyu (target ethnic group); Kikuyu (ethnicity teacher); Male (gender); Bachelor degree (Education level).

b Target-Specific Stereotypic Attitude.

c In-group effects: targeted ethnic group is the same as the ethnic group of the teacher.

combat stereotyping:

If for example you think that a Kikuyu is a thief, and then you move further from Kisumu and you go to my school, then you find that in my school, there are Kikuyus there, but they don't steal. I can leave my items there on the table and I still find it then, it disapproves whatever you know. But if you stay in Kisumu, learn in Kisumu then you will still continue having the same stereotype in your mind. So that movement is important. It is still the best tool. (Male, 24, Kasarani)

As about one third of the variance in semantic-differential ratings is explained by differences at the teacher-level, we examine to what extent teachers' ethnicity, gender, age, teaching experience and education level can explain this. ${ }^{14}$ The variable of ethnicity was recoded at this stage to match the ethnic groups targeted by the stereotypes with the ethnic group belonging of the teachers (Kikuyu, Luo and Kalenjin - the Maasai group is too small and is part of the group 'other'). Moreover, we omit the in-group variable, but allow for interactions between the targeted ethnic group and ethnic group belonging of the teacher, which yields a more detailed picture of in-group bias and specific out-group attitudes among Kenyan secondary school teachers (Table 4).

In the absence of variation at the school level, we fit a two-level model. With the exception of an effect of gender on the violent-gentle scale $(\beta=-0.36(0.15), p<0.05)$, the control variables do not yield any significant effects. Further research is therefore needed to establish

\footnotetext{
14 The variables 'age' and teaching experience have been grand-mean centered; 'education' is an ordinal variable that has been recoded in three categories: teaching certificate or professional bachelor, bachelor degree, master degree or higher. Most teachers have a bachelor degree.
}

what variables can explain the variation at the teacher level. ${ }^{15}$ In terms of ethnicity, we do find significant effects. Overall, the results confirm the existence of stereotype-congruent attitudes and in-group bias. While Kikuyu teachers, all else constant, do not rate their own group less trustworthy than the other ethnic groups, with the exception of the Maasai, teachers belonging to other ethnic groups do rate Kikuyu significantly less trustworthy. In terms of intelligence, second, Luo are rated significantly more intelligent than other groups - all else constant, although Kikuyu teachers do consider their own group as intelligent. Lastly, Kikuyu teachers perceive the Luo as most violent - all else constant, and attribute their own group the highest score on the violentgentle scale. Once more, other teachers see Kikuyu as less gentle as they consider themselves. The in-group bias is not unique to the Kikuyu however: the cross-level interactions involving twice the same ethnic group, are consistently more positive than other ratings, with the exception of the intelligence ratings of the Kalenjin group (Table 4).

\section{Discussion}

Our findings expose the presence of stereotype-congruent attitudes among Kenyan secondary school teachers, as well as a significant in-group bias. Like in Western contexts, these attitudes may have a considerable impact on pupils' achievement and wellbeing at school, as well as contribute to the cementing of ethnic stereotypes in society. Hereto, survey research among pupils is warranted. In the absence of the latter, we discuss teachers' perceptions of their own stereotypical behaviour based on in-depth follow-

\footnotetext{
15 Teachers' social dominance orientation could be a possible avenue for further research (see Meeusen and Kern, 2016).
} 
up interviews. Although not indicative of undeliberate actions and potentially influenced by social desirability, these interviews yield important insights into teachers' perceptions of the prevalent norms of teaching in an ethnically diverse society and their understanding of the detrimental effects of ethnic stereotyping and stereotype-informed behaviour.

Although present, most of the interviewed teachers asserted that their stereotypic attitudes would 'not come out in the open' (Female, 47 years old, Kasarani). Prior research has shown that negative group evaluations indeed do not necessarily translate into prejudiced behaviour (Ajzen \& Fishbein, 1977, in Van Ewijk, p. 1056; Devine, 1989; Fazio, 1990). Yet, in order to control the unwanted influence of stereotypes on behaviour, people have to be aware of their own bias in the first place. And, once people are aware of their bias, they also need to be motivated to react unbiased. If, on the contrary, they are not conscious of their bias, they are likely to behave in a prejudiced manner even when they are motivated not to do so (Allport, 1958, p. 321; Devine and Sharp, 2009, p. 61-67). Many teachers that were interviewed during the follow-up interviews did seem to be aware of their bias and were motivated to renounce their prejudiced behaviour: 'First of all, you need (to be) aware of that stereotype so that you will be able to now know how to deal with it' (Male, 29 years old, Kasarani). Others explained:

As teachers, we are not immune from that. When I hear you come from this community you know back in my mind I have those stereotypes, so sometimes you, I identify them. Sometimes you have to totally ignore them you know. (Male, 46 years old, Kamukunji)

Even a teacher can tend to love a student better than the other one because I know he's from a community - without even awareness. You know we do things without, even me personally maybe I can listen to the other and I leave the other one. But something comes in mind that I need to balance it, strike a balance, so that I bring that good relationship with others. (Male, age missing, Embakasi)

Not all teachers renounce prejudiced behaviour for the same reasons. Some teachers renounced stereotyping based on moral:

I think being violent mainly narrows down to the individual, not the community as a whole. It is so wrong for us to conclude something or a character trait to all of the members of this community. (Female, 20, Starehe)

Because as teachers, we understand everything too well - we know what is right, we know what is wrong. You know that if I, the kind of comment I can make, it may not offer well (for) this group or to the other group (Female, 47 years old, Kasarani).

Other teachers, on the other hand, referred to the potential disciplinary consequences of such behaviour:

Teachers are a bit careful. Maybe by filling the form (cf. survey), they may have mentioned $<$ stereotypes $>$, but when it comes to class, the student would actually report you did that (cf. stereotyping). So teachers avoid doing that in class. (Female, 53, Kasarani)

What most teachers had in common was a sense of responsibility inherent to their profession not to let their own stereotypes influence their teaching practices: 'You know a teacher is somebody who should be a role model; a teacher is not like a politician' (Male, 27 years old, Kasarani). In this light, many interviewed teachers also considered it their task to actively fight stereotyping. A Kiswahili teacher explained how she used her course material to do so:

When you are teaching literature, we have texts - the novels and plays and the short stories - some of them actually refer to those stereotypes. As a teacher we are expected now to explain to the students how damaging those stereotypes can be. (Female, 49 years old, Dagoretti)

Other teachers encouraged their pupils 'not (to) see the other party as a Kikuyu, a Luo, a Luyha' (Male, 25, Embakasi), but to 'see themselves as Kenyans' (Female, 45, Westlands). These teachers unknowingly exemplify the recategorization or common in-group identity model (Gaertner and Dovidio, 2000): they focus attention on a superordinate category, the
Kenyan nationality, which entails all ethnic groups in a single identity.

While these accounts are promising in a country that was torn apart by ethnic rivalry, the situation is not all rosy. In the first place, the interviews showed that not all teachers are necessarily aware of their own bias. One teacher that asserted not to stereotype in the classroom in the same breath expressed stereotypical views:

I have never looked at it from a tribal point of view. I look at them as students. But something really comes out well that for sure the Luo, somehow, they perform well. From my own observations most of the Kikuyus that we have, and they are majority, do not do well. You find them in most indiscipline cases - theft cases- they are the ones who will steal textbooks. (Female, 47 years old, Kasarani)

Other teachers openly admitted that stereotyping does take place, although on a lesser scale than before: 'Somehow it (cf. stereotyping) comes out in one way or another (...) Once in a while it can create some bias of accounts, but it is really on a very small magnitude' (Female, 45 years old, Lang'ata). Moreover, it would take subtle forms: 'Maybe some teachers, especially when they are punishing they may tend to favour those of their own, but not so openly' (Male, 30 years old, Kasarani). Stereotypic attitudes would also latently affect relations among the teaching staff:

If you stay with our staff members for a long time, you will see it slowly by slowly. Although it is not pronouncing, it is reflected by the groupings people will have (...) It is on a tribal basis. (Female, 47 years old, Kasarani).

One teacher therefore depicted inter-group interactions as a 'cold war' (Male, 52 years old, Starehe). Pupils, moreover, would also express stereotypic attitudes: 'When you hear students comment about the ability of the teacher to deliver, they always align them to certain tribes' (Male, 30 years old, Kasarani). Yet, not all teachers considered stereotyping to be problematic - at least not at all times:

Whatever stereotypes there are in our school and majorly in the country, it is the oversimplified version. We have not gotten to a point where it is that dark ethnicity. It is not. (Though) occasionally, it may come up, especially during political contestations. (Male, 54 years old, Starehe).

\section{Conclusion}

Teachers' stereotypes have been found to have a detrimental effect on pupils' performance and wellbeing at school, and contribute to perpetuating and cementing existing stereotypes. While many studies have been conducted in relatively stable Western contexts, so far, little research on teachers' stereotypic attitudes has been carried out in divided societies and post-conflict settings. Stereotypes of teachers' living in such contexts are nonetheless likely to be deeply entrenched as a result of having experienced inter-group conflict and/or tensions. To address this academic void, this article examined teachers' stereotypic attitudes in the ethnically divided society of Kenya based on a sample of 925 secondary school teachers from Nairobi and 68 in-depth follow-up interviews. The survey contained three semantic-differential scales to measure stereotypic attitudes that were subsequently examined in a multi-level model.

Our findings show that secondary school teachers in Nairobi do have stereotypic attitudes: Kikuyu are perceived to be more untrustworthy; Luo as more intelligent, yet more violent; and Maasai as less intelligent than other ethnic groups. We also discovered a significant in-group bias among teachers. The prevalence of teachers' attitudes did not vary significantly between schools, despite important differences in school organization, and did not depend on teachers' age, level of education, teaching experience or gender. Further research is therefore needed to examine what variables can explain the variation in strength of teachers' attitudes. Moreover, we recommend future studies to include schools in less diverse areas of the country to study the effect of school diversity in more detail.

Teachers asserted that they did not let their stereotypic attitudes influence their classroom behaviour. Many teachers we interviewed 
were aware of their bias and were motivated to react without it - the two pre-conditions identified by the literature to effectively renounce prejudiced behaviour. Some even said they actively refuted ethnic stereotypes in the classroom. Teachers did seem to feel a strong sense of duty as teachers not to behave as 'a politician' and instead be a role model. Still, teachers admitted that stereotyping persisted. It would, however, occur to a lesser extent and in more subtle forms than before. More worrisome was that not all teachers seemed aware of their own bias, while others did not necessarily consider stereotyping to be problematic. This is a cause of concern in a country where ethnic stereotypes have repeatedly been used to instigate ethnic hatred and violence. The challenge in Kenya is therefore to avoid stereotyping from becoming a tool to incite such hatred along the electoral cycle. The Kenyan Peace Education course could play an important role in this regard. Whereas the current course does not address stereotypes in society, a critical analysis of stereotypes, and their origin, mechanism and consequences, could help to prevent politicians from using ethnicity to build political support and spread ethnic hatred. If such a course is to be credible, however, any form of stereotyping on behalf of teachers, and by extent the school administration, needs to be banned.

Rather than implicit attitudes, our research measured teachers' explicit inter-group attitudes using semantic differential scales. Such attitudes are, nevertheless, susceptible to a social desirability and selfpresentation bias, and only indicative of controlled behaviour. Although predominant in the context of Africa, more and more studies in education have therefore turned to implicit measures, such as the Implicit Association Test (IAT) or affective priming (see e.g. van den Bergh et al., 2010; Kumar et al., 2015; Glock and Krolak-Schwerdt, 2014). These measures assess respondents' automatic associations between pairs of objects, most often using reaction times. ${ }^{16}$ Not only are these measures less sensitive to social desirability, they are also indicative of spontaneous, uncontrolled, behaviour (van den Bergh et al.,
2010). It would therefore be highly interesting to replicate the current study using implicit measures. So far, few studies have used implicit measures to examine ethnic prejudice, in particular in non-Western contexts. In contrast to racial (black-white) or gender (male-female) prejudice, ethnic groups are not naturally represented in opposing pairs. Lowes et al. (2017) therefore suggest to use so-called single-target IATs that ask the respondent to sort a single attitude object with good (bad) words. Although ethnic differences are often not visible, in many cases (especially in Africa) one could use names indicative of ethnic group belonging instead of pictures to assess implicit biases and stereotypes (see also van den Bergh et al., 2010).

Another promising avenue of future research, in particular in nonWestern contexts, relates to the question to what extent and how teachers' inter-group attitudes, stereotypes and biases affect their teaching practices and behaviour, and how this in turn affects and possibly shapes pupils' inter-group attitudes and behaviour. While our research in the case of Kenya clearly indicated that many teachers were aware of the risk of ethnic stereotyping creeping into their teaching practices and interactions with pupils, much more research is needed on these crucial questions, both in Kenya as well as in other multi-ethnic societies in Africa and beyond.

\section{Competing interest}

The authors have no competing interests to declare.

\section{Acknowledgements}

The authors wish to thank Cecil Meeusen, Silke Goubin, Maarten Schroyens and the colleagues of the Centre for Research on Peace and Development for their thoughtful comments on prior versions of this paper, as well as Amélie Godefroidt for her help during the data collection.

\section{Appendix A}

Table A1

Relation between school-level variable and semantic-differential scales.

\begin{tabular}{|c|c|c|c|c|c|c|}
\hline & \multicolumn{2}{|c|}{ Trustworthiness } & \multicolumn{2}{|l|}{ Intelligence } & \multicolumn{2}{|l|}{ Violent-Gentle } \\
\hline & I & II & III & IV & $\mathrm{V}$ & VI \\
\hline Intercept & $0.38(0.16)^{*}$ & $-1.46(0.17)^{* * *}$ & $1.39(0.18)^{* * *}$ & $2.39(0.19)^{* * *}$ & $-0.50(0.21)^{*}$ & $-1.20(0.23)^{* * *}$ \\
\hline Kikuyu & & Reference & & $-1.19(0.08)^{* * *}$ & & $0.73(0.10)^{* * *}$ \\
\hline Luo & & $1.69(0.10)^{* * *}$ & & Reference & & Reference \\
\hline Kalenjin & & $1.82(0.10)^{* * *}$ & & $-1.31(0.08)^{* * *}$ & & $0.54(0.10)^{* * *}$ \\
\hline Maasai & & $2.96(0.11)^{* * *}$ & & $-1.88(0.08)^{* * *}$ & & $0.85(0.10)^{* * *}$ \\
\hline In-group & & $1.71(0.13)^{* * *}$ & & $0.79(0.10)^{* * *}$ & & $1.31(0.12)^{* * *}$ \\
\hline Extra-county $^{\mathrm{a}}$ & $0.07(0.22)$ & $0.13(0.22)$ & $0.4(0.24)$ & $0.06(0.24)$ & $0.27(0.29)$ & $0.31(0.29)$ \\
\hline County $^{\mathrm{a}}$ & $0.10(0.19)$ & $0.12(0.19)$ & $-0.22(0.22)$ & $-0.21(0.21)$ & $0.12(0.26)$ & $0.12(0.26)$ \\
\hline District $^{\mathrm{a}}$ & $0.05(0.44)$ & $0.05(0.44)$ & $0.04(0.49)$ & $0.04(0.48)$ & $0.41(0.59)$ & $0.41(0.59)$ \\
\hline Private $^{\mathrm{a}}$ & $0.36(0.21)$ & $0.39(0.21)$ & $-0.40(0.22)$ & $-0.39(0.22)$ & $0.14(0.27)$ & $0.16(0.27)$ \\
\hline \multicolumn{7}{|l|}{ Variance } \\
\hline TSSA $^{\mathrm{b}}$ & 6.35 & 4.88 & 3.90 & 3.12 & 5.05 & 4.76 \\
\hline Teacher & 2.52 & 2.89 & 2.55 & 2.72 & 3.42 & 3.46 \\
\hline School & 0.01 & 0.01 & 0.06 & 0.07 & 0.11 & 0.12 \\
\hline AIC & 18241.06 & 17524.89 & 16754.9 & 16148.3 & 17737.96 & 17586.84 \\
\hline BIC & 18290.77 & 17599.45 & 16804.62 & 16222.87 & 17787.68 & 17661.4 \\
\hline
\end{tabular}

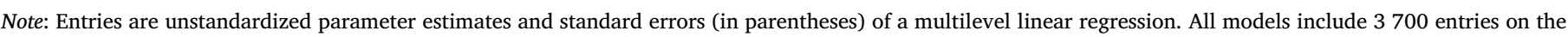
first level, 925 on the teacher level and 64 on the school level.

Significance levels: ${ }^{*} \mathrm{p}<0.05,{ }^{* *} \mathrm{p}<0.01, * * * \mathrm{p}<0.001$.

${ }^{a}$ National schools are the reference category.

b Target-Specific Stereotypic Attitude (within teacher).

\footnotetext{
${ }^{16}$ It usually involves a pair of attitude objects (e.g. black-white) and a pair of objects with positive/negative valence (e.g. good-bad). The speed of response reflects the ease with which two concepts are associated with one another.
} 


\section{References}

Abdi Ismael, J., Deane, J., 2008. The Kenyan 2007 Elections and Their Aftermath: the Role of Media and Communication. Policy Briefing No. 1. BBC World Service Trust, London.

Aboud, F.E., Levy, S.R., 2000. Interventions to reduce prejudice and discrimination in children and adolescents. In: Oskamp, S. (Ed.), Reducing Prejudice and Discrimination. Erlbaum, Mahwah, NJ, pp. 269-293.

Agirdag, O., Van Houtte, M., Van Avermaet, P., 2012. Ethnic school segregation and selfesteem: the role of teacher- pupil relationships. Urban Educ. (Beverly Hills Calif) 47 (6), 1135-1159.

Agirdag, O., Merry, M.S., Van Houtte, M., 2014. Teachers' understanding of multicultural education and the correlates of multicultural content integration in Flanders. Educ. Urban Soc. 1-27.

Albarracin, D., Hong Li, W.W., Noguchi, K., 2008. Structure of attitudes: judgments, memory, and implications for change. In: Crano, W.D., Prislin, R. (Eds.), Attitudes and Attitude Change. Psychology Press, New York, pp. 19-39.

Allport, G.W., 1958. USA. The Nature of Prejudice. Addison-Wesley Publishing Company.

Bar-Tal, D., 2002. The elusive nature of peace education. In: Salomon, G., Nevo, B. (Eds.), Peace Education: The Concept, Principles and Practice in the World. Psychology Press, New York, pp. 27-36.

Battera, F., 2012. Ethnicity and degree of partisan attachment in Kenyan politics. J. Asian Afr. Stud. 48 (1), 114-125.

Beelmann, A., Heinemann, K.S., 2014. Preventing prejudice and improving intergroup attitudes: a meta-analysis of child and adolescent training programs. J. Appl. Dev. Psychol. 35, 10-24.

Bentrovato, D., Korostelina, K.V., Schulze, M. (Eds.), 2016. History Can Bite: History Education in Divided and Postwar Societies. V\&R Unipress, Göttingen, Germany.

Branch, D., 2011. Kenya: Between Hope and Despair, 1963-2011. Yale University Press, New Haven.

Brewer, M.B., Miller, N., 1996. Intergroup Relations. Open University Press, Birmingham. Brown, C.S., Bigler, R.S., 2002. Effects of minority status in the classroom on children's intergroup attitudes. J. Exp. Child Psychol. 83, 77-110.

Bush, K.D., Saltarelli, D. (Eds.), 2000. The Two Faces of Education in Ethnic Conflict. UNICEF Innocenti Research Centre, Florence.

Chang, D.F., Demyan, A., 2007. Teachers' stereotypes of asian, Black, and white students. Sch. Psychol. Q. 22 (2), 91-114.

Dercon, S., Gutierrez-Romero, R., 2012. Triggers and characteristics of the 2007 kenyan electoral violence. World Dev. 40 (4), 731-744.

Devine, P.G., 1989. Stereotypes and prejudice: their automatic and controlled components. J. Pers. Soc. Psychol. 56, 5-18.

Devine, P.G., Sharp, L.B., 2009. Automaticity and control in stereotyping and prejudice. In: Nelson, T.D. (Ed.), Handbook of Prejudice, Stereotyping and Discrimination. Psychology Press, New York, pp. 61-87.

Dunkake, I., Schuchart, C., 2015. Stereotypes and teacher characteristics as an explanation for the class specific disciplinary practices of pre-service teachers. Teach. Teach. Educ. 50, 56-69.

Fazio, R.H., 1990. Multiple processes by which attitudes guide behavior: the MODE model as an integrative framework. In: In: Zanna, M.P. (Ed.), Advances in Experimental Social Psychology, vol. 23. Academic Press, New York, pp. 75-109.

Figlio, D.N., 2005. Names, Expectations and the Black-white Test Score Gap, NBER Working Paper, March 2005 (No.W11195). Retrieved from. http://ssrn.com/ abstract $=684721$

Gaertner, S.L., Dovidio, J.F., 2000. Reducing Intergroup Bias: the Common Ingroup Identity Model. Psychology Press, Philadelphia, PA.

Gershenson, S., Holt, S.B., Papageorge, N.W., 2016. Who believes in me? The effect of student-teacher demographic match on teacher expectations. Econ. Educ. Rev. 52, 209-224.

Glock, S., Krolak-Schwerdt, S., 2014. Stereotype activation versus application: how teachers process and judge information about students from ethnic minorities and with low socioeconomic background. J. Soc. Psychol. Educ. 17, 589-607.

Guttmann, J., Bar-Tal, D., 1982. Stereotypic perceptions of teachers. Am. Educ. Res. J. 19 (4), 519-528.

Hamilton, D.L., Sherman, S.J., Crump, S.A., Spencer-Rodgers, J., 2009. The role of entitativity in stereotyping, processes and parameters. In: Nelson, T.D. (Ed.), Handbook of Prejudice, Stereotyping and Discrimination. Psychology Press, New York, pp. 179-198.

Harneit-Sievers, A., Peters, R.-M., 2008. Kenya's 2007 general election and its aftershocks. Africa Spectr. 43 (1), 133-144.

Horner, L., Kadiwal, L., Sayed, Y., Barrett, A., Durrani, N., Novelli, M., 2015. Literature Review: The Role of Teachers in Peacebuilding. [25.10.2015 UNICEF:. ]. http:// learningforpeace.unicef.org/research/the-role-of-teachers-inpeacebuilding-2/.

Hornsby, C., 2013. Kenya: A History Since Independence. I.B. Tauris, London.

Human Rights Watch, 2008. Ballots to Bullets: Organized Political Violence and Kenya's Crisis of Governance. Human Rights Watch, New York.

Ishiyama, J., Pulido Gomez, A., Stewart, B., 2016. Does conflict lead to ethnic particularism? Electoral violence and ethnicity in Kenya 2005-2008. Nationalism Ethn. Polit. 22 (3), 300-321.

Jennings, M.K., Niemings, R.G., 1974. Political Character of Adolescence: The Influence of Families and Schools. Princeton University Press, New Jersey.

Jussim, L., Harber, K.D., 2005. Teacher expectations and self-fulfilling prophecies: knowns and unknowns, resolved and unresolved controversies. Personal. Soc. Psychol. Rev. 9 (2), 131-155.

Kumar, R., Karabenick, S.A., Burgoon, J.N., 2015. Teachers' implicit attitudes, explicit beliefs, and the mediating role of respect and cultural responsibility on mastery and performance-focused instructional practices. J. Educ. Psychol. 107 (2), 533-545.

Kuppens, Line, Langer, Arnim, 2016. Divided we teach? Teachers' perceptions of conflict and peace in Côte d'Ivoire. Peace and Conflict: J. Peace Psychol. 22 (4), 329-333.

Lowes, S., Nunn, N., Robinson, J.A., Weigel, J., 2017. Understanding ethnic identity in Africa: evidence from the implicit association test (IAT). Am. Econ. Rev.: Pap. Proc. 105 (5), 340-345.

Makinen, M., Kuira, M.W., 2008. Social Media and Post-Election Crisis in Kenya. Information \& Communication Technology Africa, 13. Retrieved from:. http:// repository.upenn.edu/ictafrica/13.

McKown, C., Weinstein, R.S., 2008. Teacher expectations, classroom context, and the achievement gap. J. Sch. Psychol. 46, 235-261.

Meeusen, C., Kern, A., 2016. The relation between societal factors and different forms of prejudice: a cross-national approach on target-specific and generalized prejudice. Soc. Sci. Res. 55, 1-15.

Ministry of Education, Science and Technology, 2014. Education Sector Policy on Peace Education. Ministry of Education, Science and Technology, Nairobi.

Mwaka, M., Kafwa, V.N., Musamas, J.K., Wambua, B.K., 2013. The national goals of education in Kenya: interrogating the achievement of national unity. J. Educ. Pract. 4 (4), 149-156.

Ndonye, M.M., Yieke, F.A., Onyango, J.O., 2015. Ethnicity as Discursive construct in Kenyan televised comedy: humorous harm? J. Pan Afr. Stud. 8 (3), 44-60.

Nyatuka, B.O., Bota, K.N., 2014. Equity in access to secondary education in Kenya: a historical perspective. J. Educ. Pract. 5 (2), 48-54.

Olson, M.A., Kendrick, R.V., 2008. Origins of attitudes. In: Crano, W.D., Prislin, R. (Eds.), Attitudes and Attitude Change. Psychology Press, New York, pp. 111-130.

Pettigrew, T.F., Tropp, L.R., 2011. When Groups Meet: the Dynamics of Intergroup Contact. Psychology Press, Philadelphia, PA.

Reyna, C., 2000. Lazy, dumb, or industrious: when stereotypes convey attribution information in the classroom. Educ. Psychol. Rev. 12 (1), 85-110.

Riley, T., Ungerleider, C., 2012. Self-fulfilling prophecy: how teachers' attributions, expectations, and stereotypes influence the learning opportunities afforded aboriginal students. Can. J. Educ. 35 (2), 303-333.

Rimé, B., Kanyangara, P., Yzerbyt, V., Paez, D., 2011. The impact of Gacaca tribunals in Rwanda: psychosocial effects of participation in a truth and reconciliation process after a genocide. Eur. J. Soc. Psychol. 41, 695-706.

Rosenthal, R., Jacobsen, L., 1968. Pygmalion in the Classroom: Teacher Expectation and Pupils' Intellectual Development. Holt, Rinehart and Winston, New York.

Salomon, G., Nevo, B. (Eds.), 2002. Peace Education: the Concept, Principles, and Practices Around the World. Psychology Press, New York.

Smith, A., Marks, C., Novelli, M., Valiente, O., Scandurra, R., 2016. Exploring the Linkages Between Education Sector Governance, Inequity, Conflict, and Peacebuilding in Kenya: Research Report Prepared for UNICEF Eastern and Southern Regional Office (ESARO). UNICEF, Nairobi.

Stangor, C., 2009. The study of stereotyping, prejudice, and discrimination within social psychology: a quick history of theory and research. In: Nelson, T.D. (Ed.), Handbook of Prejudice, Stereotyping and Discrimination. Psychology Press, New York, pp. 1-22.

Steele, C.M., 1997. A threat in the air: how stereotypes shape intellectual identity and performance. Am. Psychol. 52 (6), 613-629.

Tenenbaum, H.R., Ruck, M.D., 2007. Are teachers' expectations different for racial minority than for european american students? A meta-analysis. J. Educ. Psychol. 99 (2), 253-273.

Thijs, J., Fleischmann, F., 2015. Student-teacher relationships and achievement goal orientations: examining student perceptions in an ethnically diverse sample. Learn. Individ. Differ. 42, 53-63.

Thijs, J., Verkuyten, M., 2012. Ethnic attitudes of minority students and their contact with majority group teachers. J. Appl. Dev. Psychol. 33, 260-268.

Torney-Purta, J., 2002. The school's role in developing civic engagement: a study of adolescents in twenty-eight countries. Appl. Dev. Sci. 6 (4), 203-212.

Tropp, L., Hawi, D.R., O’Brien, T.C., Gheorghiu, M., Zetes, Alexandra, Butz, D.A., 2017. Intergroup contact and the potential for post-conflict reconciliation: studies in Northern Ireland and South Africa. Peace Confl. J. Peace Psychol. 23 (3), 239-249.

van den Bergh, L., Denessen, E., Hornstra, L., Voeten, M., Holland, R.W., 2010. The implicit prejudiced attitudes of teachers: relations to teacher expectations and the ethnic achievement gap. Am. Educ. Res. J. 47 (2), 497-527.

van Ewijk, R., 2011. Same work, lower grade? Student ethnicity and teachers' subjective assessments. Econ. Educ. Rev. 30, 1045-1058.

Yieke, F.A., 2008. the discursive construction of ethnicity: the case of the 2007 Kenyan General election. Paper Presented at the 12th General Assembly of Codesria. Yaoundé. 7-11 December 2008.

Zembylas, M., Charalambous, P., Charalambous, C., 2012. Manifestations of greek-cypriot teachers' discomfort toward a peace education initiative: engaging with discomfort pedagogically. Teach. Teach. Educ. 28 (8), 1071-1082.

Zembylas, M., Charalambous, C., Charalambous, P., 2016. Peace Education in a Conflictaffected Society: an Ethnographic Journey. Cambridge University Press, Cambridge.

Line Kuppens is a doctoral student working jointly at the Institute of Development Policy at the University of Antwerp, and the Centre for Research on Peace and Development at the University of Leuven (KU Leuven).

Arnim Langer is Director of the Centre for Research on Peace and Development (CRPD) and Associate Professor of International Relations at University of Leuven (KU Leuven), as well as Alexander von Humboldt Fellow at the University of Heidelberg.

Sulley Ibrahim is a doctoral student working at the Centre for Research on Peace and Development at the University of Leuven (KU Leuven). 